\title{
Primary Percutaneous Coronary Intervention (pPCl) Using Right Fossa Radialis (Dorsal Transradia) Approach
}

\author{
Santosh Kumar Sinha* (D), Puneet aggarwal (D) and Umeshwar Pandey \\ Department of Cardiology, LPS Institute of Cardiology, GSVM Medical College, India
}

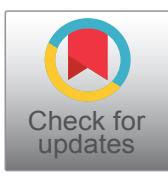

*Corresponding author: Santosh Kumar Sinha, FACC, FAESC, FSCAI, Associate Professor, Department of Cardiology, LPS Institute of Cardiology, GSVM Medical College, Kanpur, Uttar Pradesh, 208002, India, Tel: +91-9670220088, Fax: +910512-2556199; 2556521

\begin{abstract}
Haematoma, dissection, local site granuloma, and persistent radial artery occlusion are few of the complications of conventional transradial access. The distal radial artery located in the "fossa radialis or anatomical snuffbox" on the dor $\neg$ sal side of the hand may be an attractive alternative to conventional radial stick. Here, we report a case of a 47-year-old diabetic male who presented with retrosternal chest pain and sweating of 2-hours duration, and diagnosed as acute inferior wall myocardial infarction. Primary percutaneous coronary intervention of culprit right coronary artery was performed through right transradial approach using fossa radialis (dorsal Transradial).
\end{abstract}

\section{Keywords}

Anatomical snuffbox, Fossa radialis, Distal radial artery Transradial coronary intervention

\section{Introduction}

Following first report of radial percutaneous coronary intervention (PCI) by Kiemeneij in 1992, transradial access has gradually evolved, and has scored over transfemoral access for both therapeutic as well as diagnostic purpose $[1,2]$. The distal radial artery located in "fossa radialis" on dorsal side of hand may be an attractive alternative to conventional radial stick. The distal part of radial artery is located distal to superficial palmar branch of radial artery. Both palmar arches communicate with each other through collaterals, and therefore antegrade flow is maintained if any one of them undergoes occlusion.

\section{Case Report}

A 47-year-old, diabetic male presented with ret- rosternal chest pain and sweating of 2-hours duration. His physical examinations and biochemistry were unremarkable. Electrocardiogram revealed ST个 in lead II, III, and aVF with reciprocal changes in lead aVL suggesting acute inferior wall myocardial infarction. Echocardiography demonstrated mild hypokinesia in right coronary artery territory (RCA) with ejection fraction of $48 \%$. Primary $\mathrm{PCl}(\mathrm{pPCl})$ was planned after proper consent. He was preloaded with prsugrel-60 mg, aspirin- $325 \mathrm{mg}$ and atorvastatin- $80 \mathrm{mg}$. On catheterization table, local site was disinfected with povidone iodine. His right hand was bent toward his left groin and slightly abducted with thumb underneath other four fingers, thus making anatomical snuff box (ASB) more prominent. ASB is a space located in radial part of wrist, which becomes prominent when the thumb is extended (Figure 1A). It is bounded medially by tendons of abductor pollicis longus and extensor pollicis brevis muscles and laterally by tendon of extensor pollicis longus muscle (Figure 2). The base of this triangular structure is formed by extensor retinaculum. The distal radius, scaphoid, trapezium and base of the first metacarpal bone form base of this triangular area. The arterial pulse was felt as distal part of radial artery passes through ASB, and skin over it was infiltrated with $2 \mathrm{~mL}$ of $2 \%$ prilocain. It was accessed by puncturing it using $21 \mathrm{G}$ needle and $6 \mathrm{~F}$ radial hydrophilic sheath (Cordis Corp, USA) was inserted over 0.021" guide wires (Cordis Corp, USA) (Figure 1B). Spasmolytic cocktail containing 2500 units of unfractionated heparin, $200 \mathrm{mcg}$ of nitroglycerin and $2.5 \mathrm{mg}$ diltiazem was administered. Coronary angiogram was performed using 5 F TIG catheter (Terumo, Japan) which revealed sub-

Citation: Sinha SK, Aggarwal P, Pandey U (2020) Primary Percutaneous Coronary Intervention (pPCI) Using Right Fossa Radialis (Dorsal Transradia) Approach. Int J Clin Cardiol 7:198. doi.org/10.23937/23782951/1410198

Accepted: August 29, 2020; Published: August 31, 2020

Copyright: (C) 2020 Sinha SK, et al. This is an open-access article distributed under the terms of the Creative Commons Attribution License, which permits unrestricted use, distribution, and reproduction in any medium, provided the original author and source are credited. 

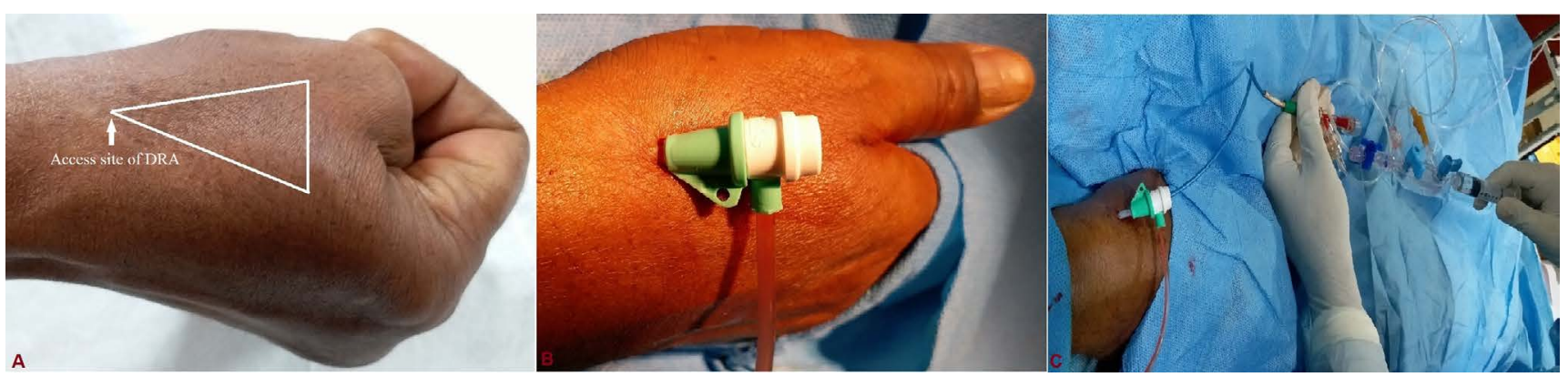

Figure 1: A) Fossa radialis is a space located (white triangle) in the radial part of the wrist which becomes prominent when the thumb is extended and white arrow indicates access site of distal radial artery (DRA); B) Radial sheath inserted in dorsal radial artery; C) Guiding catheter inserted through sheath for primary percutaneous intervention.

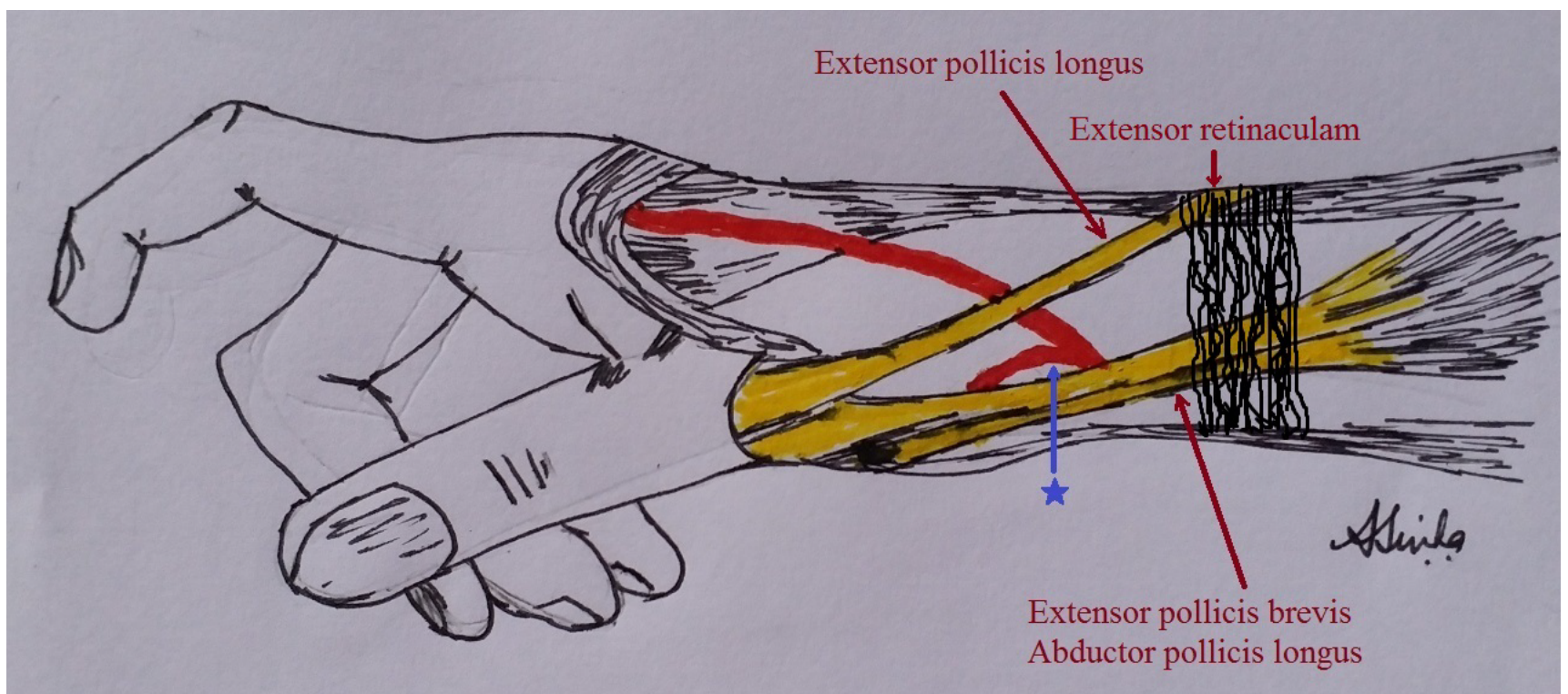

Figure 2: Anatomical boundary of fossa radialis which is bounded laterally by the tendons of extensor pollicis longus and medially by tendons of extensor pollicis brevis, and abductor pollicis longus muscle. Blue arrow and star indicates the radial artery segment typical site of cannulation.

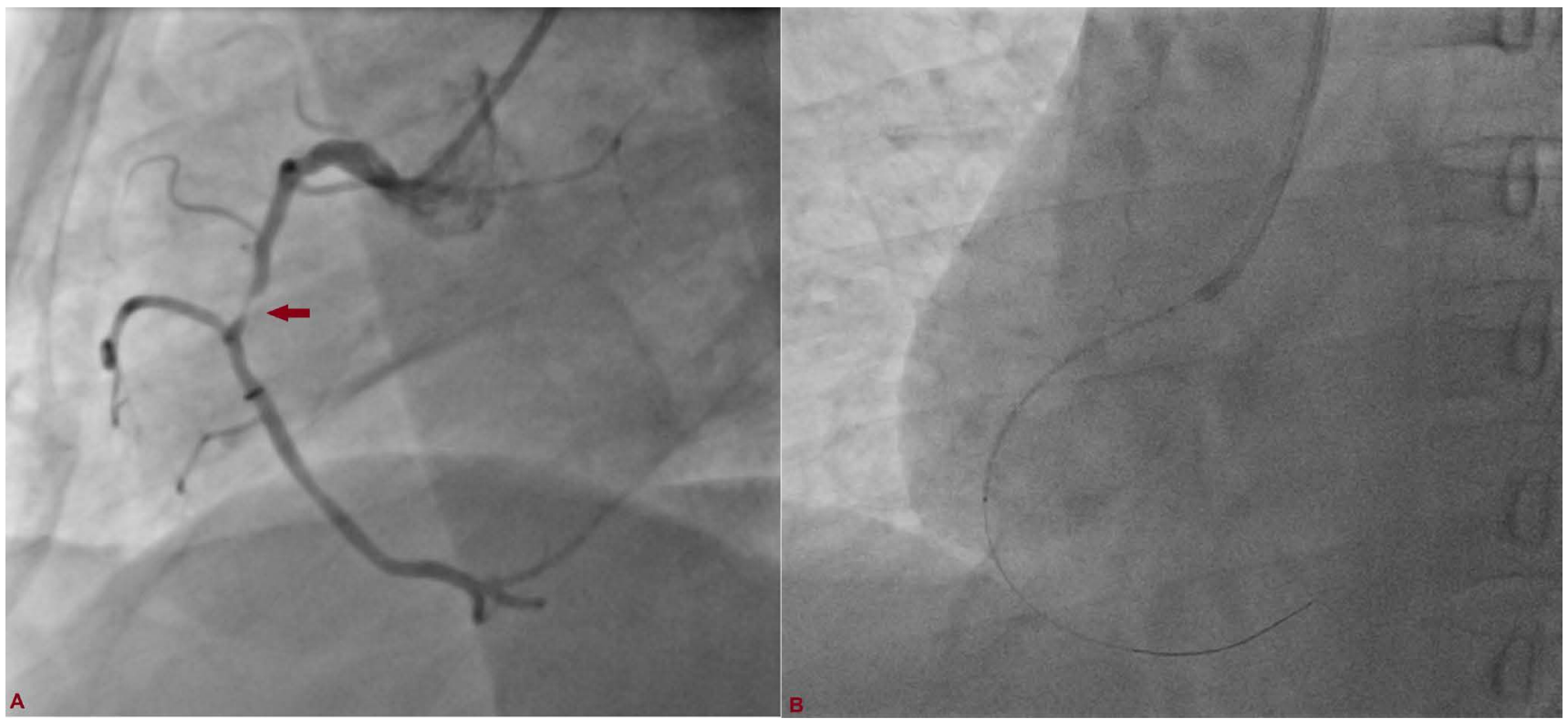

Figure 3: A) Coronary angiogram showing subtotal occlusion (red arrow) of mid right coronary (RCA); $B) 2.75 \times 38 \mathrm{~mm}$ Xience Prime (everolimus eluting stent, Abott, USA) after being positioned across the lesion. 
total occlusion of proximal RCA while left system was normal (Figure 3A). 4,000 $U$ of heparin was given further, and RCA was cannulated with 6F FR catheter (Femoral right, Boston Scientific, USA) (Figure 1C) 0.014" runthrough wire (terumo, Japan) was parked distally and lesion was pre-dilated with $2 \times 10 \mathrm{~mm}$ Minitrak balloon (Abott, USA). It was stented by deploying $2.75 \times 38 \mathrm{~mm}$ Xience Prime (everolimus eluting stent, Abott, USA) at 12 atm pressure achieving TIMI 3 flow (Figure 3B, Figure $4 \mathrm{~A}$ and Figure 4B).

His symptoms and ECG stabilised. At the end of the procedure, radial sheath was pulled out and early haemostasis was obtained by compression with thumb for approximately $15 \mathrm{~min}$ (Figure $5 \mathrm{~A}$ ). When bleeding was stopped, a light compressive bandage with gauze was applied over access site for 2-3 hours. Right radial artery pulse at forearm and ASB was checked by palpation next day, and found patent after examined by vascular Doppler (Figure 5B and Figure 5C). He was discharged with aspirin-150 mg/day, prasugrel-10 mg/day, atorvastatin- $80 \mathrm{mg} /$ day, metoprolol- $100 \mathrm{mg} /$ day and ramipril-2.5 mg/day. Patient is doing fine since then with regular follow-up at our institute.

\section{Discussion}

Distal radial artery (DRA) access from fossa radialis was described for first time by Babunashvili, et al., when they opened occluded ipsilateral radial arteries in retrograde fashion [3]. Use of right arm allows a natural working position for operator as it can be brought comfortably towards left side of the patient. Furthermore, operator can work as usual from right side of patient as he will be in close proximity to patient's hand. It also cuts down radiation exposure as operator stays at a safer distance from radiation source. Arm position during intervention is also comfortable for the patient as he does not have to expose palmar side of arm and no other equipment is required to support patient's wrist. It also helps in keeping conventional or proximal transradial access as a reserve option in case of failure of distal access using fossa radialis. Otherwise, one needs to switch to contralateral site which will further increase procedural time which is very important in case of acute STEMI.

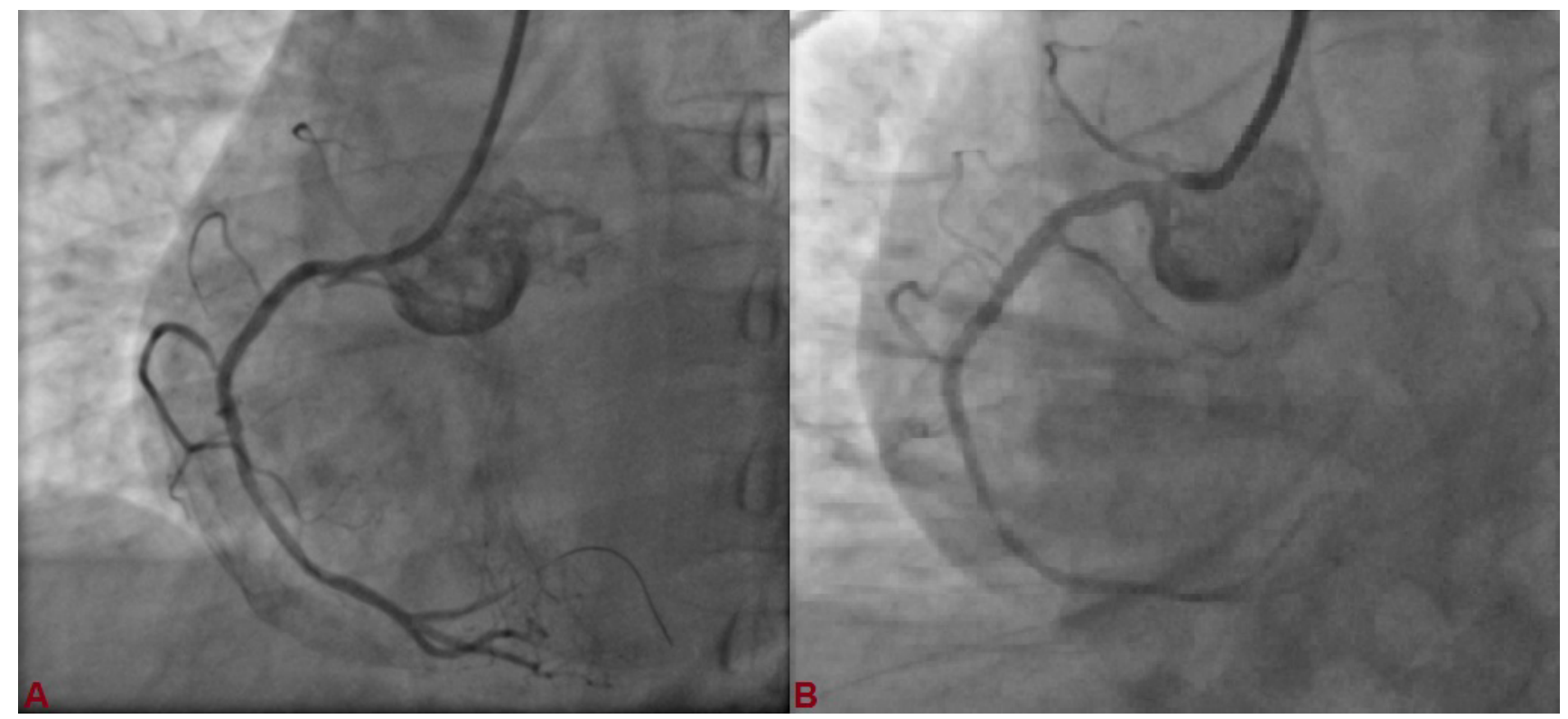

Figure 4: A) Stent deployed at 12 atm pressure; B) Post-procedural TIMI III flow in RCA.
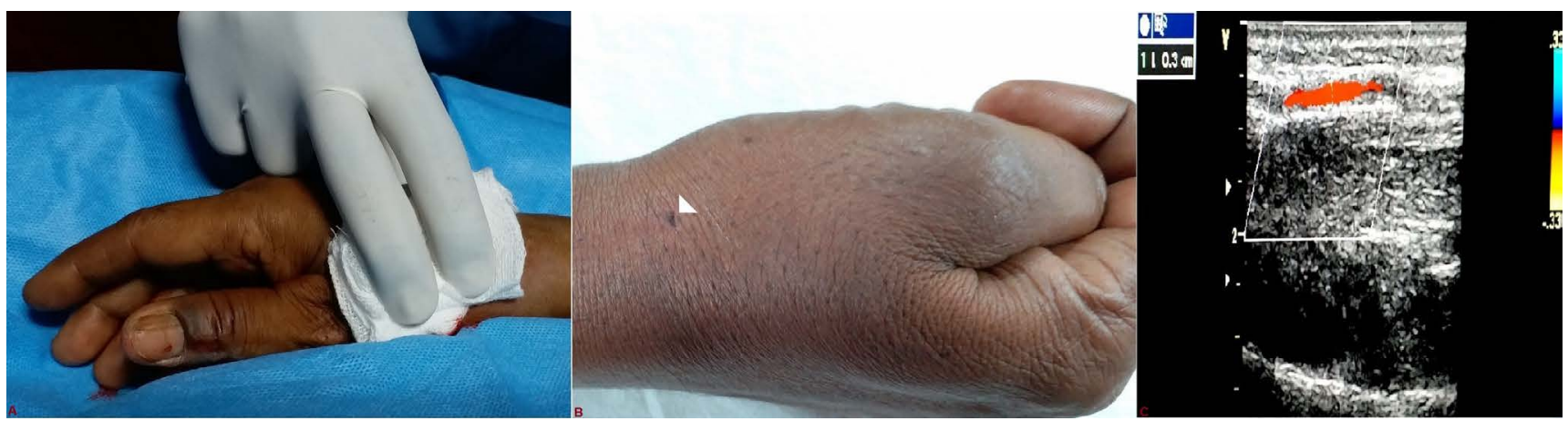

Figure 5: A) Early haemostasis was obtained by compression with the thumb for approximately 15 min after the radial sheath was pulled out; B) Local puncture site next day (white arrow head); C) The right distal radial artery was found patent next day after examined by vascular doppler. 
With transradial intervention peaking gradually, many atraumatic and refined hardwares (hydrophilic radial sheath) are now available which makes this approach much safer. Among published literature, calibre of distal radial artery varies because of difference in ethnicity, measurement methods, body surface area and body mass index [4]. Average diameter of distal radial was reported as $2.4 \mathrm{~mm}$ as observed by Kaledin, et al. which indicates that it can easily incorporate $6 \mathrm{~F}$ sheath through which most of interventions including bifurcation and chronic total occlusion can be performed [5]. In a study among Japanese population, average diameter was found to be $2.6 \pm 0.5 \mathrm{~mm}$ by Norimatsu, et al. [6]. Similarly, it was reported as $2.41 \pm 0.50 \mathrm{~mm}$ in left hand and $2.36 \pm 0.49 \mathrm{~mm}$ in right hand among Korean population as reported by Lee, et al. $[7,8]$. In their series of 637 patients as reported by Babunashvili, et al. $5 \mathrm{~F}$ and $6 \mathrm{~F}$ sheaths were used in $91 \%$ and $9 \%$ cases for diagnostic and therapeutic purposes with overall success of $98 \%$ [3]. In another larger series of 2,884 patients as reported by Kaledin, et al. $6 \mathrm{~F}$ and $7 \mathrm{~F}$ sheath were used in $98 \%$ and $1 \%$ patients respectively for $\mathrm{PCl}$ [9]. This shows safety of this approach.

Distal radial artery traverses beneath the tendons at the medial boundary of snuff box to continue as deep palmar branch of radial artery which later forms deep palmar arch. In fossa radialis, superficial branch of radial nerve and cephalic vein run in close vicinity to the artery [10]. There is potential to injuries to these structures particularly the nerve though not reported in any patients in study by reported by Soydan, et al. [5] but one should be careful while making multiple attempts to prevent their injury. Persistent radial artery occlusion, arteriovenous fistula, compartment syndrome, radial pseudoaneurysm, haematoma, and spasm are few of frequently reported complications of proximal radial access which are less frequent in fossa radialis approach [9]. Overall, radial artery occlusion was reported in $0.4 \%$, hematoma in $0.2 \%$, pulsatile hematoma in $<0.1 \%$, infection in $0.1 \%$, dissection in $0.1 \%$, and arteriovenous fistula in $<0.1 \%$ patients [9]. As this vessel is small and superficial, compression time is also shorter which helps in achieving early haemostasis (15 minutes vs. $1 \mathrm{~h}$ ) and complete haemostasis (1h vs. $3 \mathrm{~h}$ ) compared to conventional radial access [5]. As it is performed by manual compression, it is cost effective as no transradial band (TR) is needed. It also lowers down risk of congestion of hand, numbness, sterile granuloma, and rarely pressure necrosis.

Also, if artery gets completely occluded within snuff box, antegrade blood flow stays intact through superficial palmar arch which minimizes risk of thrombosis, extensive forearm radial artery occlusion, ischaemia and hand disability [10]. Because of anatomical location and absence of muscle compartment, it totally negates compartment syndrome [10]. Furthermore, radial artery remains preserved which can be used for future catheterization, arteriovenous shunt, and harvesting for coronary bypass grafting. It can be used as an alternative site in cases of radial spasm which is often induced by failed radial puncture at wrist level as flow from ulnar artery maintains perfusion in fossa radialis.

Being an evolving technique, it requires certain learning curve. Main reasons for failure are failed puncture and failure to advance guidewire due to tortuosity and vasospasm. Therefore, this technique may not be suitable for unselected patients as in substantial number of patients; no clear pulse is palpable in fossa radialis. Complex high risk PCI (CHIP) is difficult to be performed using this approach. Since access site is more distal, regular length catheters $(100 \mathrm{~cm})$ may be too short to cannulate coronary arteries especially in taller patients and extra length catheters (110 or $115 \mathrm{~cm}$ ) may be required in such patients. Therefore, this access is not a "solution in search of a problem" but certainly it can be considered in patients who prefer or require a procedure where artery is well palpable in anatomical snuffbox. As it has been shown that radial is better, smaller is better, distal radial is even better! With the advent of refined hardwares (sheath and guiding catheters), this approach becoming the default for cardiac catheterization will no longer be a dream.

\section{Conflict of Interest}

None.

\section{Sources of support (if applicable)}

Disclosure of funding received for this work from any of the following organizations: National Institutes of Health (NIH); Welcome Trust; and other(s) - None.

\section{Statement of Equal Authors' Contribution}

All authors made equal contribution.

\section{References}

1. Kiemeneij F, Laarman GJ, de Melker E (1995) Transradial artery coronary angioplasty. Am Heart J 129: 1-7.

2. Agostoni $P$, Biondi-Zoccai GGL, de Benedictis ML, Rigattieri S, Turri M, et al. (2004) Radial versus femoral approach for percutaneous coronary diagnostic and interventional procedures; systematic overview and meta-analysis of randomized trials. J Am Coll Cardiol 44: 349-356.

3. Babunashvili A, Dundua D (2011) Recanalization and reuse of early occluded radial artery within 6 days after previous transradial diagnostic procedure. Catheter Cardiovasc Interv 77: 530-536.

4. Cai G, Huang H, Li F, Shi G, Yu X, et al. (2020) Distal transradial access: A review of the feasibility and safety in cardiovascular angiography and intervention. BMC Cardiovasc Disord 20: 356-360.

5. Soydan E, Akın M (2018) Coronary angiography using the left distal radial approach - An alternative site to conventional radial coronary angiography. Anatol J Cardiol 19: 243-248.

6. Norimatsu K, Kusumoto T, Yoshimoto K, Tsukamoto M, Kuwano T, et al. (2019) Importance of measurement of the 
diameter of the distal radial artery in a distal radial approach from the anatomical snuffbox before coronary catheterization. Heart Vessels 34: 1615-1620.

7. Parikh A, Jia KQ, Lall SK, Shah RS, Gilchrist IC (2020) Distal radial and ulnar arteries: The alternative forearm access. Curr Treat Options Cardiovasc Med 22: 1-5.

8. Pitta SR, Prasad A (2020) Accessing the wrist: From data to tips and tricks. Interv Cardiol Clin 9: 1-19.

9. Corcos T (2019) Distal radial access for coronary angiography and percutaneous coronary intervention: A state-ofthe-art review. Catheter Cardiovasc Interv 93: 639-644.

10. Davies RE, Gilchrist IC (2018) Back hand approach to radial access: The snuff box approach. Cardiovasc Revasc Med 19: 324-326. 